\title{
Transformation by FosB requires a trans-activation domain missing in FosB2 that can be substituted by heterologous activation domains
}

\author{
Ron Wisdom, Jeffrey Yen, ${ }^{1}$ Dana Rashid, and Inder M. Verma \\ Molecular Biology and Virology Laboratory, The Salk Institute, San Diego, California 92186-5800 USA
}

Two functionally distinct proteins derived from the FosB gene by alternative splicing have recently been described. FosB protein transforms fibroblasts efficiently, whereas FosB2 protein, a carboxy-terminally truncated form of FosB, does not, despite the fact that both proteins can participate in high-affinity, sequence-specific DNA binding as part of a heterodimeric complex with c-Jun protein. We show here that the functional difference between these proteins is the result of the presence of a potent proline-rich transcriptional activation domain in the carboxy-terminal amino acids unique to FosB. This conclusion is supported by three lines of evidence: (1) Mutations in the carboxy-terminal region of FosB that impair transcriptional activation also reduce transforming potential, despite the fact that DNA binding as part of a complex with c-Jun is not affected; (2) the carboxy-terminal region unique to Fos $B$ functions as an activation domain when fused to the DNA-binding domain of GAL4; and (3) transforming potential can be conferred on FosB2 by fusing any of several different well-characterized trans-activation domains. These results identify an additional functional requirement for transformation by Fos proteins and have implications for the mechanism(s) of mitogenic signaling by the AP-1 transcription complex.

[Key Words: FosB protein; FosB2 protein; trans-activation domain; transformation]

Received December 17, 1991; revised version accepted February 18, 1992.

Treatment of cells with peptide growth factors induces a cascade of biochemical events that results in cell division. Prominent among these is a rapid increase in the transcription of early response genes, an event that does not require de novo protein synthesis. The early response genes encode several transcription factors that are believed to mediate, at least in part, the cellular response to growth factors. The members of the Fos gene family, including c-Fos, FosB, Fra-1, and Fra-2, are induced by growth factors. The products of these genes form heterodimeric complexes with Jun proteins that bind to and increase transcription from genes that contain phorbol ester (12-O-tetradecanoylphorbol-13-acetate)-responsive elements (TREs) (Angel et al. 1987; Halazonetis et al. 1988; Nakabeppu et al. 1988; Rauscher et al. 1988; Sassone-Corsi et al. 1988; Kouzarides and Ziff 1989; Neuberg et al. 1989; Turner and Tjian 1989; for review, see Ransone and Verma 1990). That the products of the Fos family of genes mediate the response to growth factors is suggested further by the observation that deregulated expression of some of these genes, including c-Fos and FosB, can induce neoplastic transformation of estab-

'Present address: Department of Molecular Biology, Schering-Plough Re-
search, Bloomfield, New Jersey 07052 USA. lished rodent fibroblasts (Miller et al. 1984; Mumberg et al. 1991; Yen et al. 1991).

Analysis of mutant Fos genes supports the hypothesis that transcriptional activation by the Fos-Jun complex is the mechanism by which Fos genes induce neoplastic transformation. The products of all transforming mutants of Fos display high-affinity binding to TRE sites as part of a Fos-Jun complex. Conversely, all mutant proteins that do not interact with either Jun or DNA do not retain transforming activity (Scheurmann et al. 1989). The interactions with Jun and DNA are mediated by discrete domains known as the leucine zipper and basic region, respectively (Halazonetis et al. 1988; Nakabeppu et al. 1988; Rauscher et al. 1988; Sassone-Corsi et al. 1988; Kouzarides and Ziff 1989; Neuberg et al. 1989; Turner and Tjian 1989). Thus, transforming activity is dependent on the integrity of the basic region and leucine zipper (BLZ) motif (Scheurmann et al. 1989). Previous studies have also demonstrated that transformation by Fos proteins requires sequences outside the BLZ motif, including sequences in the carboxyl terminus (Jenuwein and Muller 1987; Lucibello et al. 1991). Although the function of these sequences is not well understood, by analogy with other transcription factors in which the DNA-binding and activation functions are separa- 
ble, they may function as transcriptional activation domains.

Recently, we and others have identified two functionally distinct products derived from the FosB gene by alternative splicing (Dobrzanski et al. 1991; Mumberg et al. 1991; Nakabeppu and Nathans 1991; Yen et al. 1991). FosB protein is a 338 -amino-acid protein that was originally identified as the product of the FosB gene, an early response gene with strong homology to c-Fos (Zerial et al. 1989). FosB2 is a 237-amino-acid protein derived from a separate mRNA that is missing the carboxy-terminal 101 amino acids of FosB as a result of an alternate splicing event. We have shown previously that the two messages are coinduced after serum stimulation of starved cells with somewhat delayed kinetics compared with the c-Fos gene (Yen et al. 1991). FosB protein transforms established fibroblasts efficiently, whereas FosB2 protein does not (Mumberg et al. 1991; Yen et al. 1991). Both FosB and FosB2 contain the highly conserved BLZ motif, and both proteins form a heterodimeric complex with c-Jun and bind to DNA in a sequence-specific manner with high affinity. Therefore, the difference in transforming potential between these genes is not the result of inefficient interaction with DNA. In this report we show that the carboxy-terminal 101 amino acids unique to FosB comprise a potent transcriptional activation domain and that the presence or absence of this domain is responsible for the difference in transforming activity between FosB and FosB2. These results identify a functional requirement aside from DNA binding for transformation by Fos proteins. They suggest further that optimal mitogenic signaling by the AP-1 transcription complex requires the presence of an activation domain on the Fos partner.

\section{Results \\ Transformation by FosB but not FosB2}

We and several other groups have recently described the existence of two distinct proteins derived from the FosB gene by alternative splicing (Dobrzanski et al. 1991; Mumberg et al. 1991; Nakabeppu and Nathans 1991; Yen et al. 1991). To analyze the transforming potential of FosB and FosB2 proteins, the respective cDNAs were introduced into the retroviral vector SLX-CMV (Scharfmann et al. 1991). Stocks of recombinant helper-free virus were used to infect $208 \mathrm{~F}$ cells, a rodent fibroblast cell line sensitive to transformation by FosB. Infected cells were selected with G418 and expanded as a mass culture. Northern analysis of RNA isolated from infected cells shows high-level expression of mRNAs of the expected size (Fig. 1A). Little, if any, of the FosB mRNA derived from the CMV promoter is spliced to give FosB2 mRNA (Fig. 1A). In contrast, upon induction of the endogenous FosB mRNA, $\sim 50 \%$ is spliced (Yen et al. 1991), demonstrating that the efficiency of splicing is dependent on sequences outside the FosB-coding region. Immunoprecipitation of metabolically labeled cell extracts with an- tiserum specific for FosB demonstrates that large amounts of FosB and FosB2 proteins are produced in infected cells relative to the amount seen after serum stimulation of serum-starved cells (Fig. 1B).

The 208F cells infected with the retroviruses SLXCMV-FosB or SLX-CMV-FosB2 were used to analyze various parameters related to transformation. Following infection, cells were split and duplicate plates were used to monitor the appearance of foci of transformed cells and G418-resistant colonies. The number of transformed foci in plates of cells infected with the SLX-CMV-FosB virus is approximately equal to the number of G418resistant colonies, whereas SLX-CMV-FosB2 does not give rise to foci of transformed-appearing cells (Table 1). G418-resistant cells infected with SLX-CMV-FosB display marked morphologic evidence of transformation, with a refractile, rounded appearance, whereas FosB2expressing cells are indistinguishable from the parental 208F cells (Fig. 1C). Pooled colonies of FosB-expressing cells grow to form large colonies in soft agar, whereas FosB2-expressing cells do not (data not shown). Thus, by three different criteria, morphology, focus formation, and anchorage-independent growth, FosB, and not FosB2, transforms $208 \mathrm{~F}$ fibroblasts efficiently.

\section{The carboxy-terminal region of Fos $B$ is required for transformation}

The structural differences between FosB and FosB2, shown schematically in Figure 2, must underlie the distinct biologic properties of these two proteins. We have shown previously that both proteins can bind to DNA in a sequence-specific manner as part of a heterodimeric complex with c-Jun protein (Yen et al. 1991). This result is not unexpected, as both proteins contain the conserved BLZ region that mediates these interactions. Therefore, complex formation and DNA binding do not explain the biologic difference between these proteins. The carboxy-terminal region unique to FosB contains a proline-rich segment similar to the activation domains of some transcription factors (Mermod et al. 1989). To define sequences in the carboxy-terminal region of FosB required for transformation, FosB genes encoding mutations in the carboxy-terminal 101 amino acids were generated. The mutations correspond to a deletion of the amino acids encoded by the alternate intron (D238-284), a deletion of amino acids encoded by sequences downstream of the alternate intron (284-338), and deletion of a proline-rich stretch (10 of 18 residues, including 7 consecutive prolines; see Fig. 2) encoded within the intron. Coupled in vitro transcription and translation of the mutant genes showed that all constructs produced proteins of the expected size (data not shown). Electrophoretic mobility-shift assays (EMSAs) showed that all of the mutant proteins can bind to DNA containing AP-1 sites as part of a heterodimeric complex with c-Jun (Fig. 3). Therefore, any difference in the biologic activity of these mutant proteins is not the result of altered DNA-binding activity. 


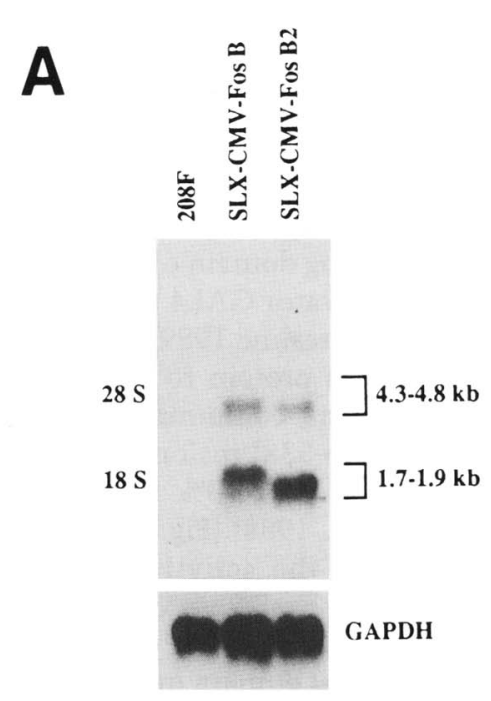

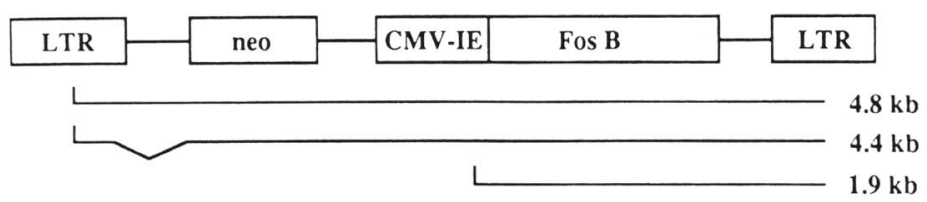

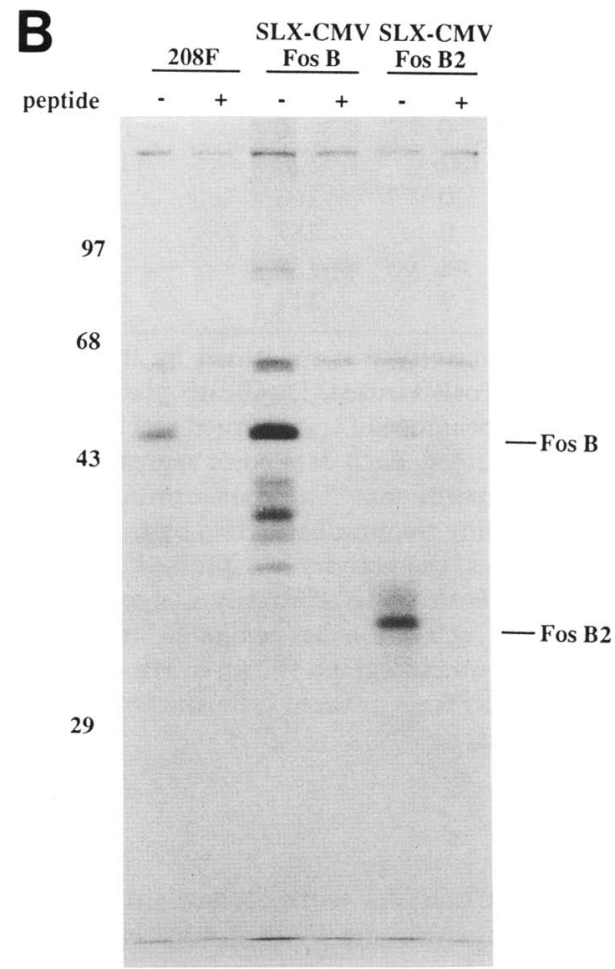

C

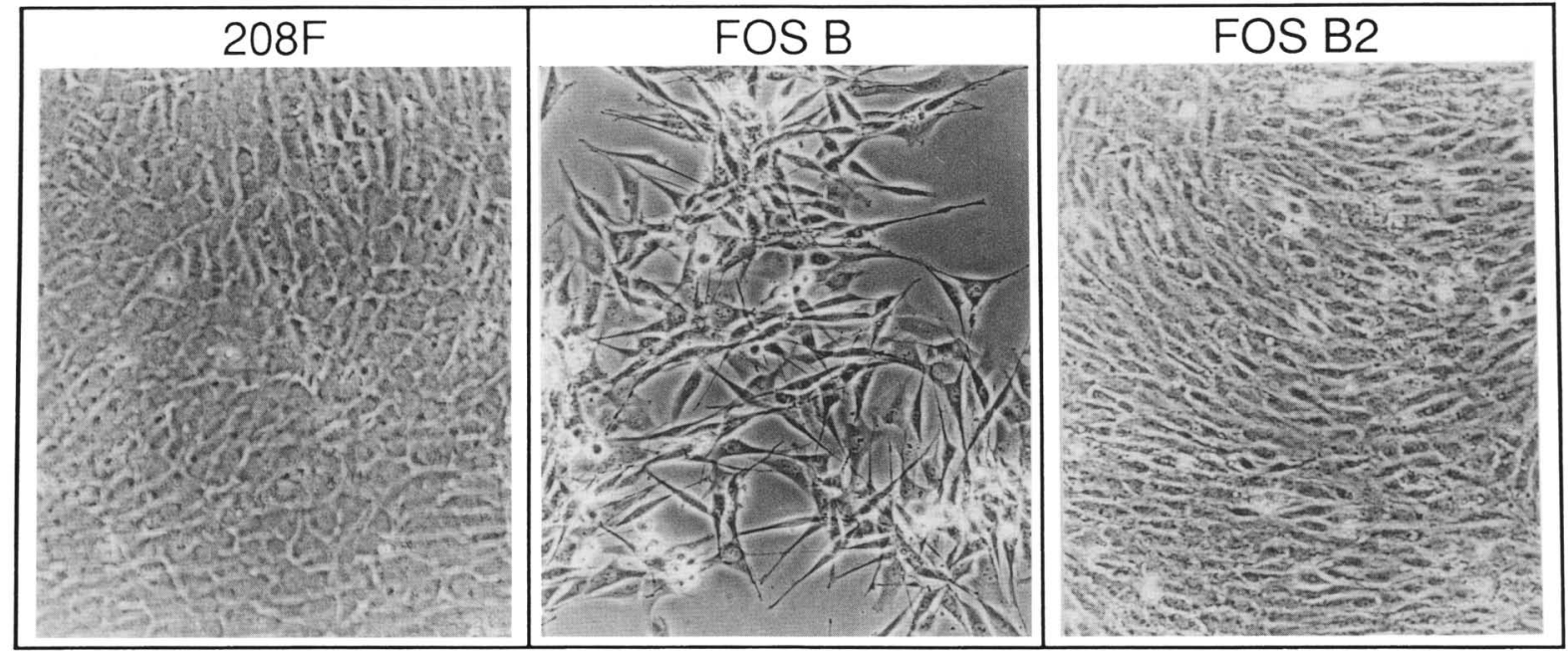

Figure 1. Expression of FosB and FosB2 in infected 208F cells. (A) RNA expression in infected 208F cells. RNA was isolated from uninfected $208 \mathrm{~F}$ cells and G418-resistant $208 \mathrm{~F}$ cells infected with recombinant retroviruses containing the FosB or FosB2 cDNAs. Northern blotting and hybridization with a FosB probe shows the presence of three transcripts from virally infected cells. In the original autoradiograph, faint bands of $4.6-4.8 \mathrm{~kb}$, corresponding to unspliced transcripts originating from the long terminal repeat (LTR), are observed. A schematic of the transcripts generated in FosB-infected cells is shown below. The corresponding transcripts in FosB2-infected cells are all $\sim 140$ nucleotides shorter. $(B)$ Immunoprecipitation of FosB proteins in infected 208F cells. Exponentially growing infected $208 \mathrm{~F}$ cells and uninfected $208 \mathrm{~F}$ cells stimulated with serum were labeled with ${ }^{35} \mathrm{~S}$-labeled amino acids for 90 min. Extracts of labeled cells were incubated with antisera directed against a peptide comprised of FosB amino acids 80-96 in either the absence $(-)$ or presence $(+)$ of competing peptide, and the immunoprecipitate was separated by SDS-PAGE. The extracts were boiled before immunoprecipitation so that Jun peptides, which migrate very close to FosB on SDS-PAGE, would not be visualized. $(C)$ Phase-contrast photomicrographs of $208 \mathrm{~F}$ cells and infected cells expressing FosB or FosB2. Original magnification, $160 \times$. 
Table 1. Focus-forming activity of FosB proteins

\begin{tabular}{lcccr}
\hline & Foci/plate & $\begin{array}{l}\text { G418 } \\
\text { colonies/ } \\
\text { plate }\end{array}$ & $\begin{array}{l}\text { Transforming } \\
\text { activity } \\
(\%)\end{array}$ & $\begin{array}{l}\text { Transin } \\
\text { mRNA } \\
(\%)\end{array}$ \\
\hline None & 0 & 0 & NA & 0 \\
FosB & 132 & 120 & 100 & 100 \\
FosB2 & 0 & 163 & 0 & 12 \\
D237-284 & 0 & 287 & 0 & 3 \\
D284-338 & 42 & 152 & 27 & 35 \\
D256-275 & 2 & 111 & 2 & 4 \\
\hline
\end{tabular}

Focus-forming activity was measured by infecting $208 \mathrm{~F}$ cells with different FosB viruses. Duplicate plates were then analyzed for the appearance of transformed foci and G418-resistant colonies as described. Each data point represents the average of two separate experiments. The transforming activity was calculated by dividing the number of foci by the number of G418resistant colonies; the activity is expressed as percentage, with the activity of FosB virus arbitrarily assigned a value of 100 . Transcriptional activation is generated from densitometric analysis of the autoradiograph shown in Fig. $4 \mathrm{C}$, with a value of $100 \%$ assigned to FosB-infected cells and $0 \%$ assigned to uninfected $208 \mathrm{~F}$ cells.

The mutant cDNAs were cloned into the SLX-CMV vector, and recombinant virus stocks were used to infect 208F cells as described. G418-resistant cells were expanded as a mass culture and analyzed for expression of FosB mRNA by Northern blotting (Fig. 4A). Each of the mutant viruses directed the expression of approximately equal amounts of FosB mRNA. Immunoprecipitation of metabolically labeled COS cells transfected with the mutant cDNAs showed that proteins of the expected sizes were expressed at approximately equal levels, except for mutant D284-338, which was expressed at a level severalfold lower (Fig. 4B). Focus assays were performed with cells infected with the mutant viruses as described. Mutant D284-338 induced focus formation at $27 \%$ the level of the wild-type FosB virus, whereas mutants D237-284 and D256-275 induced transformation at $0 \%$ and $2 \%$ the level of FosB, respectively (Table 1 ). These results demonstrate that transforming activity is strongly dependent on the presence of amino acids encoded within the alternate intron. The transin gene encodes an extracellular matrix-degrading enzyme and has been shown to be a direct target of transcriptional activation by the Fos-Jun complex (Matrisian et al. 1986; Kerr et al. 1988). As a measure of transcriptional activation by FosB, we analyzed the amount of transin mRNA in stably infected cells by Northern analysis (Fig. 4C). Quantitation of transin mRNA levels as determined by scanning densitometry is shown in Table 1 . We consistently observe a small increase in transin mRNA in FosB2-infected cells compared with uninfected 208F cells, suggesting that FosB2 is not totally deficient in transcriptional activation. Nonetheless, it is clear that the level of transin mRNA is greatly increased in FosBinfected cells compared with FosB2-infected cells (Fig. 4 C).
The carboxy-terminal region of Fos $B$ contains a trans-activation domain

The strong correlation between transcriptional activation of the transin gene and neoplastic transformation suggests that the carboxy-terminal domain unique to FosB constitutes a functional activation domain. We have tested this hypothesis in two ways. First, we have linked the carboxy-terminal 113 amino acids of FosB to the DNA-binding domain of the well-characterized transcriptional activator GAL4 (Kakidani and Ptashne 1988; Sadowski and Ptashne 1989) and tested the ability of the resulting fusion protein to activate transcription of reporter constructs containing GAL4-binding sites. The GAL4-FosB(226-338) fusion protein is a transcriptional activator, with $\sim 20-30 \%$ the activity of GAL4-VP16 (Sadowski et al. 1988) (Fig. 5). GAL4-FosB(226-284) retains $\sim 50 \%$ of the activity of the parental construct, whereas GAL4-FosB(284-338) does not display detectable activity (Fig. 5). These results demonstrate that the carboxy-terminal domain unique to FosB can function as a trans-activation domain when linked to a heterologous DNA-binding domain. Furthermore, the sequence shown to be required for transcriptional activation and transformation in FosB is required for efficient activation when linked to GAL4. In both contexts, the presence of the amino acids encoded by the alternate intron, which includes the proline-rich segment, is required to maintain functional activity.

\section{Functional substitution by heterologous} trans-activation domains

Many studies have demonstrated an ability of transcriptional activation domains to function in a context other than the native protein. If the difference in transforming potential between FosB and FosB2 is the result of the presence of a transcriptional activation domain in FosB, then it should be possible to create chimeric transforming genes by fusing heterologous activation domains onto FosB2. To test this hypothesis, chimeric genes were constructed in which FosB2 sequences were fused to sequences encoding the well-characterized trans-activation domains from VP16, CTF/NF1, and SP1 (Fig. 6A) (Courey and Tjian 1988; Triezenberg et al. 1988; Mermod et al. 1989|. These trans-activation domains are representative of the acidic, proline-rich, and glutaminerich classes, respectively. The fusion genes were tested for their ability to induce neoplastic transformation in focus-forming assays (Table 2). All of the fusion genes scored positive in the transformation assays; FosB2-CTF and FosB2-SP1 each had $\sim 20 \%$ the activity of FosB, whereas FosB2-VP16 induced transformation approximately as efficiently as FosB. Not all sequences can convert FosB2 into a transforming gene; a random segment of Escherichia coli DNA encoding a 68-amino-acid open reading frame was inactive (data not shown). Furthermore, transformation by FosB2-VP16 requires the ability to interact with c-Jun, as a derivative of this construct with a deletion of the leucine zipper domain did not 

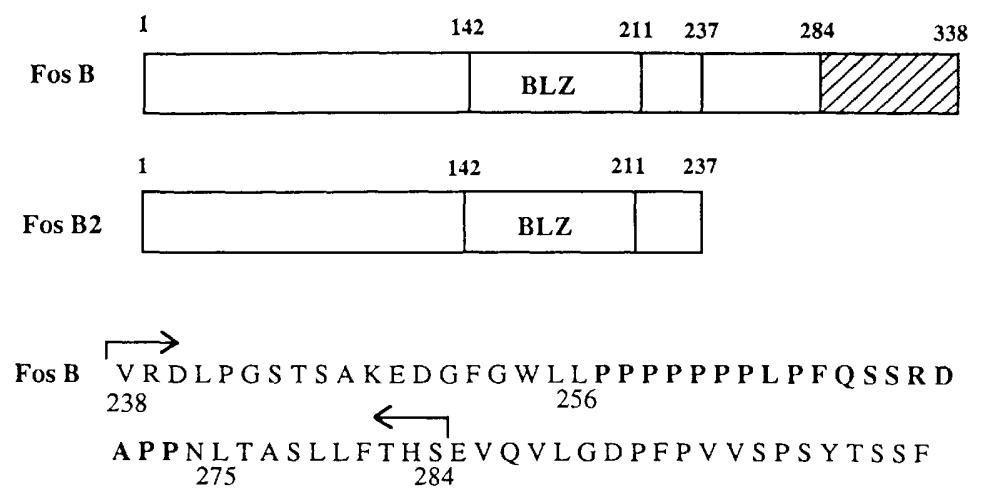

VLTCPEVSAFAGA QRTSGSEQPSDPLNSPSLLA L Stop 338
Figure 2. Schematic diagram of the structures of FosB and FosB2 proteins. FosB and FosB2 are identical in amino acids $1-237$, including the BLZ motif, which is highly conserved among Fos family members (amino acids 142-211). Because of an alternate splicing event, translation of FosB2 is terminated after amino acid 237, whereas FosB contains a unique 101amino-acid carboxy-terminal extension. The carboxyterminal extension of FosB consists of amino acids encoded within the alternate intron (amino acids 238 284; stippled box), and amino acids encoded downstream of the intron (amino acids 285-338; hatched box). The amino acid sequence of this region is shown; the brackets designate the amino acids encoded within the alternate intron. The proline-rich segment is shown in boldface type; the numbers refer to amino acid position. induce transformation (data not shown). Northern analysis of RNA from infected cells again revealed a strong correlation between expression of transin mRNA and transforming potential (Fig. 6B), supporting the hypothesis that transcriptional activation is the mechansim of transformation by FosB. We conclude that fusion of three different well-characterized activation domains can confer transforming activity on FosB2.

\section{Discussion}

The existence of two functionally distinct proteins from the FosB gene has been described recently. FosB efficiently transforms established rodent fibroblasts, whereas FosB2, a truncated form of FosB generated by alternate splicing, does not (Mumberg et al. 1991; Yen et al. 1991). Three lines of evidence support the conclusion that the difference between FosB and FosB2 with regard to transforming activity is the result of the presence of a strong transcriptional activation domain in the carboxyterminal region unique to FosB. First, mutants in this region with impaired induction of transin mRNA expression also show diminished transforming potential. Second, this region functions as a trans-activation domain when linked to the DNA-binding domain of GAL4, and mutations of the fusion gene corresponding to those in the native FosB molecule have similar effects on transcriptional activation in either context. Finally, fusion of three different well-characterized trans-activation domains can confer transforming potential on FosB2. The activation domain that we have identified contains many proline residues, similar to the proline-rich activation domain in the transcription factor CTF-1 (Mermod et al. 1989), and our experiments demonstrate an important role for the proline residues in mediating the activation function. The biochemical interaction in which this domain directly participates remain to be elucidated.

An absolute requirement for the presence of the BLZ motif for transformation by Fos proteins has been demonstrated previously (Neuberg et al. 1989; Scheurmann et al. 1989). In addition, it has been shown that se-

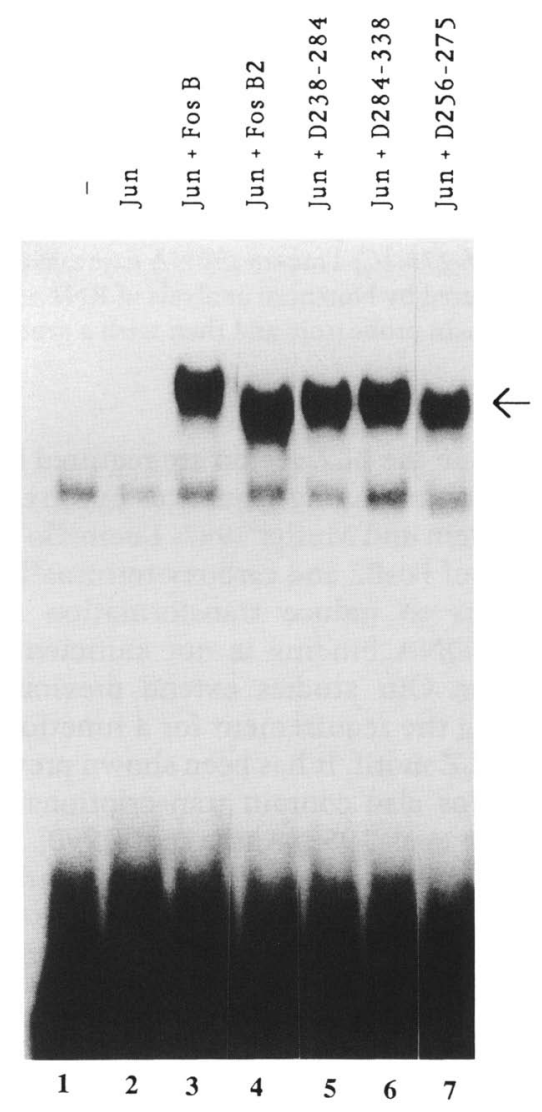

Figure 3. FosB mutants form DNA-binding complexes with c-Jun. Mutant FosB proteins were mixed with c-Jun protein generated by in vitro translation in rabbit reticulocyte lysate. The proteins were then incubated with a ${ }^{32} \mathrm{P}$-labeled 20 -bp fragment corrsponding to the human collagenase gene AP-1 site, and complexes were resolved by electrophoresis on nondenaturing polyacrylamide gels. The mutant FosB proteins are named according to the deleted amino acids. The arrow designates the position of the specific FosB/c-Jun complex. In addition, a more rapidly migrating complex is formed from proteins present in the reticulocyte lysate. 


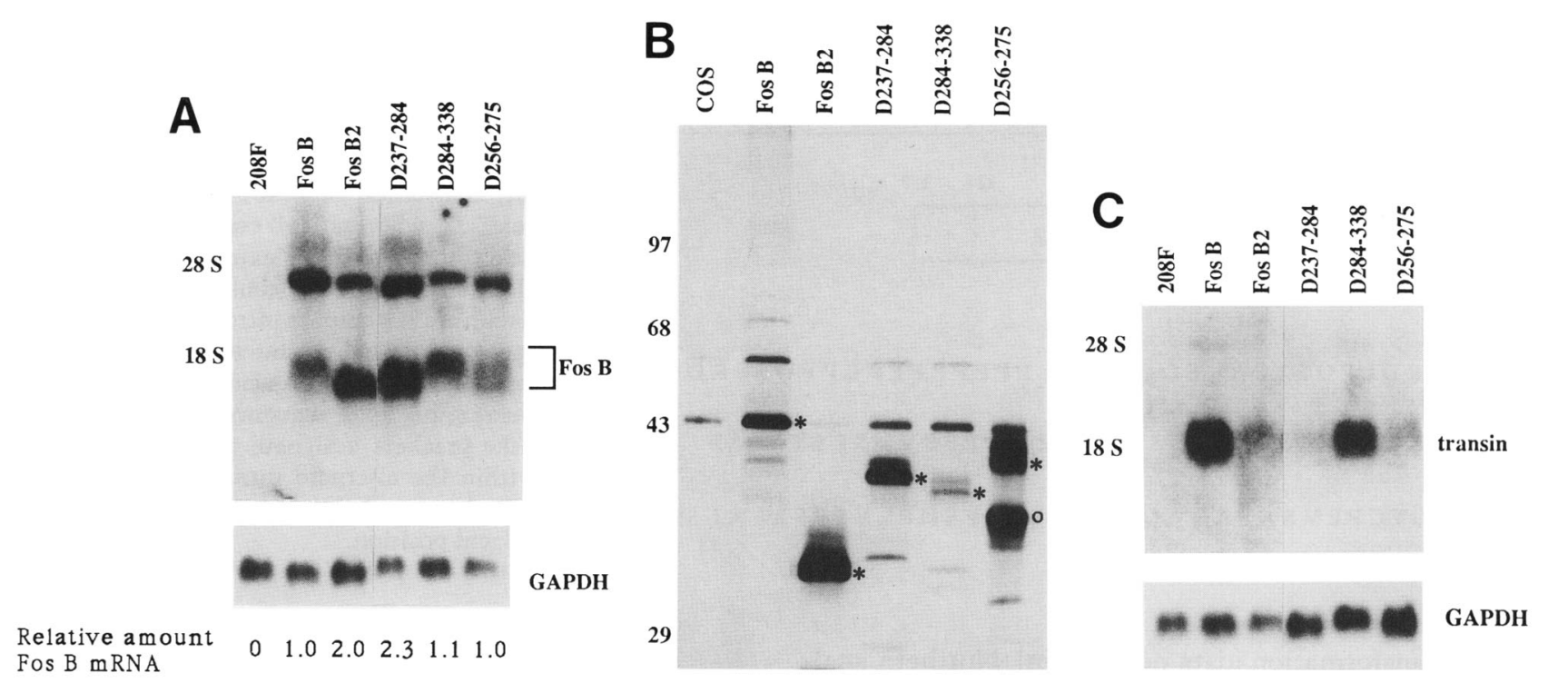

Figure 4. Expression of mutant FosB genes. (A) Expression of FosB RNA in infected 208F cells. RNA was isolated from G418-resistant $208 \mathrm{~F}$ cells infected with retroviruses carrying different FosB mutants (the nomenclature designates the FosB amino acids deleted). (Top) The RNA was analyzed by Northern blotting with a FosB probe. The positions of the rRNAs are shown (for a diagram of the expected transcripts, see Fig. 1). (Bottom) The same filter was hybridized with a probe for GAPDH as loading control. The relative amount of FosB mRNA for each mutant was determined by scanning densitometry of the autoradiographs after adjusting for differences in loading using the GAPDH signal. $(B)$ Expression of mutant FosB proteins. COS cells transiently transfected with plasmids expressing the different FosB mutants were metabolically labeled with ${ }^{35} \mathrm{~S}$-labeled amino acids, and immunoprecipitated FosB proteins were separated by SDS-PAGE. The positions of the mutant proteins (*) and the molecular mass standards are shown. $(O)$ A presumed proteolytic product of D256-275. (C) Transin mRNA expression in cells expressing mutant FosB proteins. Transcriptional activation of the transin gene was measured by Northern analysis of RNA isolated from cells grown in the absence of serum for 24 hr. The filter was hybridized first with a transin probe (top) and then with a probe for GAPDH as a loading control (bottom). The positions of the rRNAs are shown.

quences outside the BLZ region are required for transformation by $\mathrm{v}$-fos, including sequences in the carboxyl terminus (Jenuwein and Muller 1987; Lucibello et al. 1991). The inability of FosB2 and carboxy-terminally truncated $v$-Fos mutants to induce transformation shows that high-affinity DNA binding is not sufficient to induce transformation Our studies extend previous work by demonstrating the requirement for a functional domain outside the BLZ motif. It has been shown previously that $\mathrm{v}$-Fos and c-Fos also contain transcriptional activation domains (Lech et al. 1988; Abate et al. 1990). FosB, c-Fos, and v-Fos are all highly divergent in their carboxy-terminal regions, and it is tempting to speculate that the increased transforming potential of v-Fos is the result of the presence of a stronger transcriptional activation domain in this region.

These results have important implications with regard to mitogenic signaling by the AP-1 complex, which is composed of both homodimeric Jun complexes and heterodimeric Fos-Jun complexes. It is clear that dimer formation and, hence, DNA binding, is increased by the presence of Fos protein, but the importance of trans-activation domains contributed by the various partners has been difficult to establish. If one assumes that transformation is the result of prolonged mitogenic stimulation by the AP-1 complex, it is apparent from our data that maximal mitogenic signaling requires the presence of an activation domain on the Fos partner. This does not ex- clude the existence of such domains on the Jun partner, and there is strong evidence that such domains exist (Angel et al. 1989; Bohmann and Tjian 1989; Baichwal and Tjian 1990).

It has recently become apparent that multiple isoforms of some transcription factors, including CTF/NF1 and mTFE3, are generated by alternate splicing (Santoro et al. 1988; Roman et al. 1991). In both of the cases mentioned, the different isoforms differ by the presence or absence of activation domains, allowing the generation of negative regulatory proteins. The FosB/FosB2 system represents another example of this phenomenon, supporting the idea that alternative splicing is an important mechanism in the control of transcriptional regulatory proteins.

\section{Materials and methods}

\section{Cells and transfections}

The $208 \mathrm{~F}$ cells were grown in Dulbecco's minimal essential media (DMEM) supplemented with $10 \%$ fetal calf serum (FCS). Focus-forming assays were performed by growing cells in DMEM supplemented with $5 \%$ FCS and $2 \times 10^{-6} \mathrm{M}$ dexamethasone as described previously (Wisdom and Verma 1990). To generate retroviral stocks, Am12 cells were transfected with recombinant proviral DNA using the calcium phosphate method. After selection in G418 $(400 \mu \mathrm{g} / \mathrm{ml})$, supernatants were used to infect $208 \mathrm{~F}$ cells. After infection, $208 \mathrm{~F}$ cells were split 
A

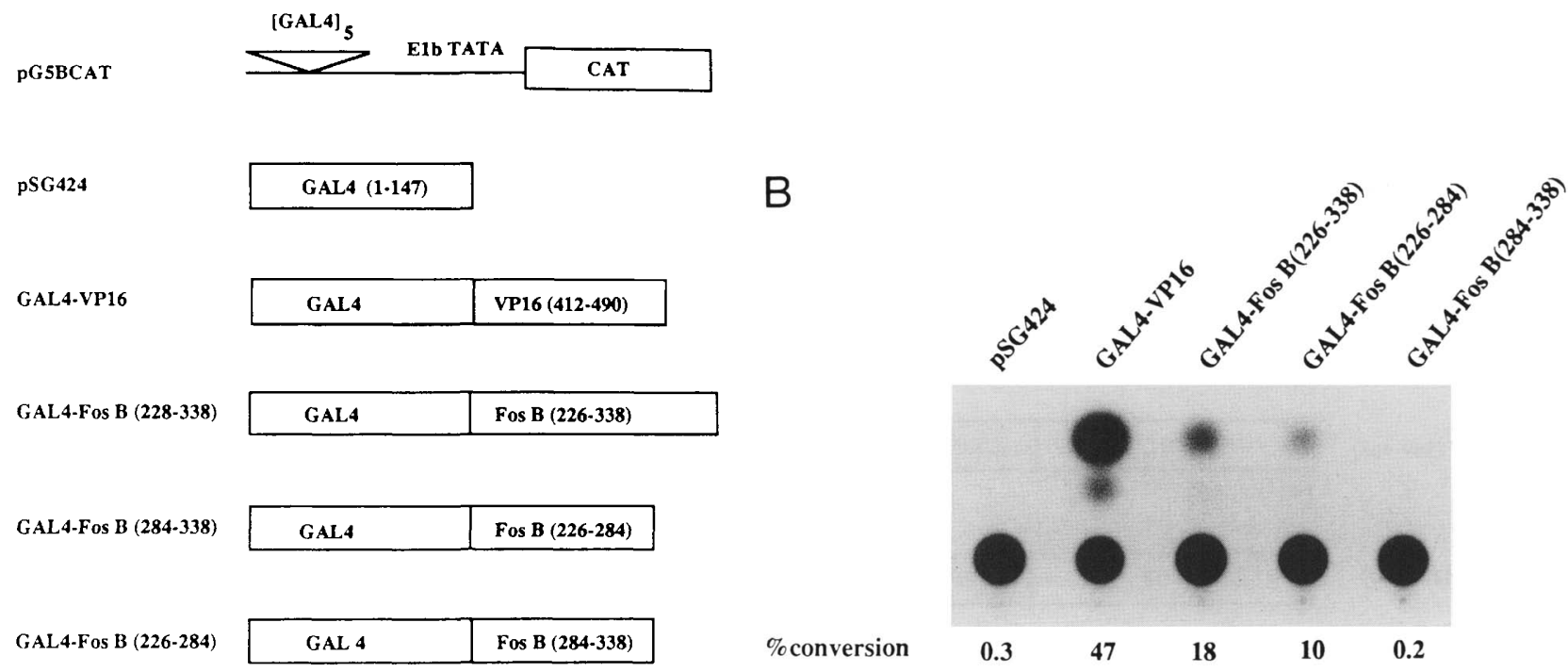

Figure 5. The carboxy-terminal domain unique to FosB contains a transcriptional activation domain. $(A)$ The carboxy-terminal domain of FosB (amino acids 226-338) or portions of the carboxy-terminal domain were fused to the DNA-binding domain of GAL4 (amino acids 1-147). A schematic diagram of the reporter construct and the different activator constructs is shown. The nomenclature refers to the amino acids of FosB fused to the DNA-binding domain of GAL4 (amino acids 1-147). (B) The fusion genes were transfected into $208 \mathrm{~F}$ cells along with the GAL4 reporter construct pG5BCAT. Forty-eight hours after transfection, cell lysates were prepared and CAT activity was measured.

into duplicate plates; one plate was selected with G418 1400 $\mu \mathrm{g} / \mathrm{ml}$ ), and the other was used to count the number of transformed foci 12 days after infection. COS cells were transfected by the calcium phosphate method. For CAT assays, $208 \mathrm{~F}$ cells were also transfected by the calcium phosphate method.

\section{Plasmid constructions}

The FosB and FosB2 cDNAs have been described previously (Yen et al. 1991). The mutant FosB cDNAs were constructed using oligonucleotide-directed mutagenesis. The mutants are named according to the amino acids deleted in the FosB cDNA. All mutants were cloned into the vector SLX-CMV (Scharfmann et al. 1991) to generate recombinant proviral DNA and into the vector pCMX (Umesono et al. 1991) for expression in COS cells.

To generate GAL4-FosB fusion genes, the polymerase chain reaction (PCR) was used to amplify various segments of the FosB genes encoding the specified amino acids. Each primer contained a $5^{\prime}$ EcoRI site and a $3^{\prime} \mathrm{Xbal}$ site; PCR-amplified fragments were then cloned into the vector pSG424, which encodes the DNA-binding domain (amino acids 1-147) of GAL4 in a SV40-based expression construct (Sadowski and Ptashne 1989). The plasmid encoding GAL4-VP16 has been described previously (Sadowski et al. 1988). The reporter plasmid pG5BCAT contains five tandem repeats of the GAL4 DNAbinding site, basal promoter sequences derived from the adenovirus E1b gene, and the CAT sequences and has been described previously (Kakidani and Ptashne 1988).

To generate FosB2 fusion genes, unique BglII and EcoRI sites were introduced into the FosB cDNA downstream of codon 237. The trans-activation domains of VP16, CTF-1, and SP1 were amplified using PCR, and the appropriate fragments were then ligated to the FosB2 sequences. The segments fused to FosB2 encode amino acids 412-490 of VP16 (Triezenberg et al. 1988), amino acids 369-468 of CTF-1 (Mermod et al. 1989), and amino acids 263-405 of SPl (Courey and Tjian 1988). A deletion of codons 183-211, corresponding to a deletion of the leucine zipper, was introduced into the FosB2-VP16 fusion cDNA by oligonucleotide-directed mutagenesis. To fuse random segments of DNA to FosB2, E. coli genomic DNA was digested with $B a m H I$ and EcoRI, and fragments of $300-700$ bp were purified by electrophoresis. The fragments were ligated downstream of codon 237 by using the FosB mutant described above. A fusion gene with an open reading frame of 307 amino acids $(237$ from FosB, 2 from the BglII sequence, and 68 from E. coli DNA) was used. Each mutant was then cloned into the retroviral vector SLX-CMV to generate proviral DNA.

Oligonucleotide-directed mutagenesis was carried out according to the method of Kunkel (Kunkel et al. 1987). The sequences of all mutants were verified by nucleotide sequencing.

\section{EMSA}

FosB and c-Jun proteins were translated in vitro using rabbit reticulocyte lysate programmed with in vitro-transcribed RNA encoding the appropriate protein. For EMSA, samples of the proteins were mixed with a ${ }^{32} \mathrm{P}$-end-labeled 20 -bp fragment corresponding to the human collagenase AP-1 site as described previously (Yen et al. 1991).

\section{RNA analysis, immunoprecipitations, and CAT assays}

RNA isolation and Northern blotting were carried out as described previously (Wisdom and Lee 1991). For transin mRNA measurement, cells were grown in DMEM with $0.5 \%$ FCS for 24 hr prior to RNA isolation.

For immunoprecipitations of $208 \mathrm{~F}$ cells, subconfluent 100 $\mathrm{mm}$ dishes were radiolabeled with $500 \mu \mathrm{Ci} / \mathrm{ml}$ of ${ }^{35} \mathrm{~S}$-labeled amino acids (Express label, NEN). Serum-starved 208F cells 


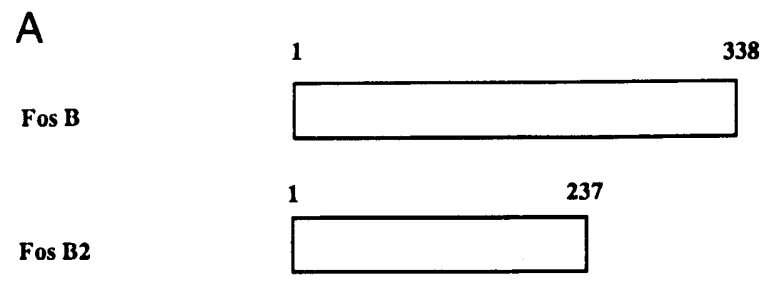

Fos B2-VP16 (412-490)

\begin{tabular}{|l|l|}
\hline Fos B2 & VP16 \\
\hline
\end{tabular}

Fos B2-CTF (369-468)

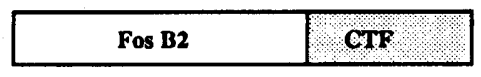

Fos B2-SP1 (263-405)

\begin{tabular}{|l|l|}
\hline Fos B2 & SP1 \\
\hline
\end{tabular}

B

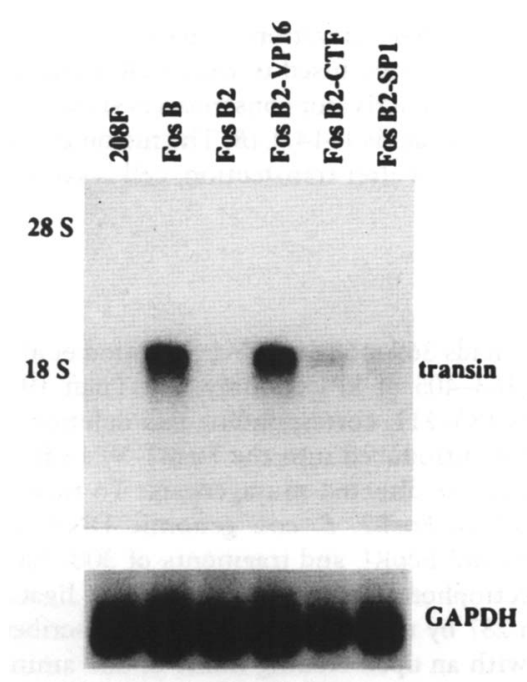

Figure 6. Transin mRNA expression in cells infected with FosB2 fusion genes. (A) FosB2 fusion genes containing transactivation domains derived from VP-16, CTF-1, and SPl were generated. Schematic diagrams of the fusion proteins are shown. $(B)$ The $208 \mathrm{~F}$ cells infected with retroviruses expressing the different fusion genes were grown in the absence of serum for $24 \mathrm{hr}$; RNA was then isolated and analyzed for transin expression (top) and GAPDH (bottom) by Northern blotting. The positions of the rRNAs are shown.

were radiolabeled in 10\% FCS (dialyzed); 208F cells infected with FosB- or FosB2-expressing viruses were labeled in media containing $0.5 \%$ FCS to reduce the expression of endogenous FosB proteins. After labeling for $90 \mathrm{~min}$, lysates were prepared in RIPA with $0.5 \%$ SDS. After boiling for $5 \mathrm{~min}$, the lysates were diluted with RIPA to $0.1 \%$ SDS. Immunoprecipitations were carried out using antisera raised against a peptide corresponding to FosB amino acids $80-96$ and protein A-Sepharose. The immunoprecipitates were separated by SDS-PAGE and visualized by autoradiography.

For immunoprecipitations of transfected COS cells, $60-\mathrm{mm}$ dishes of cells were labeled with $500 \mu \mathrm{Ci} / \mathrm{ml}$ of ${ }^{35} \mathrm{~S}$-labeled
Table 2. Transforming activity of FosB2 fusion genes

\begin{tabular}{lrrrr}
\hline & Foci/plate & $\begin{array}{l}\text { G418 } \\
\text { colonies/ } \\
\text { plate }\end{array}$ & $\begin{array}{l}\text { Transforming } \\
\text { activity } \\
(\%)\end{array}$ & $\begin{array}{l}\text { Transin } \\
\text { mRNA } \\
\langle \%\rangle\end{array}$ \\
\hline None & 0 & 0 & NA & 0 \\
FosB & 207 & 228 & 100 & 100 \\
FosB2 & 0 & 291 & 0 & 8 \\
FosB2-VP16 & 421 & 359 & 128 & 132 \\
FosB2-CTF & 19 & 202 & 11 & 21 \\
FosB2-SP1 & 42 & 154 & 30 & 23 \\
\hline
\end{tabular}

Recombinant retroviruses containing FosB2 genes with carboxy-terminal fusions of different trans-activation domains (VP16, CTF-1, and SP1) were used to perform focus-forming assays as described previously. Each data point represents the average of two separate experiments. The transforming activity was calculated by dividing the number of foci by the number of G418-resistant colonies; the activity is expressed as a percentage, with the activity of FosB virus arbitrarily assigned a value of 100. Transcriptional activation is computed from densitometric analysis of the autoradiograph shown in Fig. 6, with FosB-infected cells assigned a value of $100 \%$ and $208 \mathrm{~F}$ cells assigned a value of $0 \%$.

amino acids $24 \mathrm{hr}$ after transfection. Immunoprecipitations were then performed as described above. COS cells have high basal levels of FosB compared with $208 \mathrm{~F}$ cells.

For CAT assays, $208 \mathrm{~F}$ cells were transfected with $1 \mu \mathrm{g}$ of the $\beta$-gal expression plasmid BAG, $2 \mu \mathrm{g}$ of the reporter plasmid pG5BCAT, and $4 \mu \mathrm{g}$ of the activator construct by the calcium phosphate method. Forty-eight hours after transfection, lysates were collected and CAT activity was measured as described previously (Gorman et al. 1987). All samples were normalized for transfection efficiency by using equal amounts of $\beta$-gal activity. The experiment was performed in duplicate three separate times.

\section{Acknowledgments}

We thank Jun-ichiro Inoue for critical reading of the manuscript and members of the Verma laboratory for helpful discussions and ideas. The plasmid encoding GAL4-VP16 was a gift from Ivan Sodrowski. Raphael Scharfmann provided retroviral packaging cells and advice regarding their use, and suggested the experiments using the leucine zipper deletion mutant of FosB2VP16. Kazuhiko Umesono generously provided the expression vector pCMX. Pat McClintock helped in preparation of the manuscript. This work was supported by a grant from the University of California Tobacco Related Disease Research Program (R.W.) and National Institutes of Health grant CA44360A to I.M.V. I.M.V. is an American Cancer Society Professor of Molecular Biology.

The publication costs of this article were defrayed in part by payment of page charges. This article must therefore be hereby marked "advertisement" in accordance with 18 USC section 1734 solely to indicate this fact.

\section{References}

Abate, C., D. Luk, E. Gagne, R. Roeder, and T. Curran. 1990. Fos and Jun cooperate in transcriptional regulation via heterologous activation domains. Mol. Cell. Biol. 10: 5532-5535. 
Angel, P., M. Imagawa, R. Chiu, B. Stein, R.J. Imbra, H.J. Rahmsdorf, C. Jonat, P. Herrlich, and M. Karin. 1987. Phorbol ester-inducible genes contain a common cis element recognized by a TPA-modulated trans-acting factor. Cell 49: 729-739.

Angel, P., T. Smeal, J. Meek, and M. Karin. 1989. jun and v-jun containmultiple regions that participate in transcriptional activation in an interdependent manner. New Biologist 1: 35-43.

Baichwal, V.J. and R. Tjian. 1990. Control of c-Jun activity by interaction of a cell-specific inhibitor with regulatory domain $\delta$ : Differences between v- and c-Jun. Cell 63: 815-825.

Bohmann, D. and R. Tiian. 1989. Biochemical analysis of transcriptional activation by Jun: differential activity of c- and v-Jun. Cell 59: 709-717.

Courey, A.J. and R. Tjian. 1988. Analysis of Spl in vivo reveals multiple transcriptional domains, including a novel glutamine-rich activation motif. Cell 55: 887-898.

Dobrzanski, P., T. Noguchi, K. Kovary, C.A. Rizzo, P.S. Lazo, and R. Bravo. 1991. Both products of the fos B gene, FosB and its short form, FosB/SF, are transcriptional activators in fibroblasts. Mol. Cell. Biol. 11: 5470-5478.

Gorman, C.M., L.F. Moffatt, and B.H. Howard. 1987. Recombinant genomes which express chloramphenicol acetyltransferase in mammalian cells. Mol. Cell. Biol. 2: 1044-1051.

Halazonetis, T.D., K. Georgopoulos; M.E. Greenberg, and P. Leder. 1988. C-jun dimerizes with itself and with c-fos, forming complexes of different DNA binding affinities. Cell 55: 917924.

Jenuwcin, T. and R. Muller. 1987. Structure-function analysis of fos protein: A single amino acid change activates the immortalizing potential of v-fos. Cell 48: 647-657.

Kakidani, H. and M. Ptashne. 1988. GAL4 activates gene expression in mammalian cells. Cell 52: 161-167.

Kerr, L.D., J.T. Holt, and L.M. Matrisian. 1988. Growth factors regulated transin gene expression through $\mathrm{c}$-fos dependent and c-fos independent pathways. Science 242: 1424-1428.

Kouzarides, T. and E. Ziff. 1989. Leucine zippers of Fos, Jun and GCN4 dictate dimerization and thereby control DNA binding. Nature 340: $568-571$.

Kunkel, T.A., J.D. Roberts, and R.A. Zakour. 1987. Rapid and efficient site-directed mutagenesis without phenotypic selection. Methods Enzymol. 154: 367-382.

Lech, K., K. Anderson, and R. Brent. 1988. DNA-bound Fos proteins activate transcription in yeast. Cell 52: 179-184.

Lucibello, F.C., M. Neuberg, T. Jenuwein, and R. Muller. 1991. Multiple regions of $\mathrm{v}$-fos protein involved in the activation of API-dependent transcription: Is trans-activation crucial for transformation. New Biologist 3: 671-677.

Matrisian, L.M., P. Leroy, C. Ruhlmann, M.-C. Gesnel, and R. Breathnach. 1986. Isolation of the oncogene and epidermal growth factor-induced transin gene: Complex control in rat fibroblasts. Mol. Cell. Biol. 6: 858-867.

Mermod, N., E.A. O'Neill, T.J. Kelly, and R. Tiian. 1989. The proline-rich transcriptional activator of CTF/NF-I is distinct from the replication and DNA binding domain. Cell 58: 741-753.

Miller, A.D., T. Curran, and I.M. Verma. 1984. c-fos protein can induce cellular transformation: A novel mechanism of activation of a cellular oncogene. Cell 36: 51-60.

Mumberg, D., F.C. Lucibello, M. Schuermann, and R. Muller. 1991. Alternative splicing of $f \circ B$ transcripts results in differentially expressed mRNAs encoding functionally antagonistic proteins. Genes \& Dev. 5: 1212-1223.

Nakabeppu, Y. and D. Nathans. 1991. A naturally occurring truncated form of FosB that inhibits Fos/Jun transcriptional activity. Cell 64: 751-759.

Nakabeppu, Y., K. Ryder, and D. Nathans. 1988. DNA binding activities of three murine iun proteins: Stimulation by fos. Cell 55: 907-915.

Neuberg, M., M. Schuermann, J.B. Hunter, and R. Muller. 1989. Two functionally different regions in Fos are required for the sequence-specific DNA interaction of the Fos/Jun complex. Nature 338: 589-590.

Ransone, L.J. and I.M. Verma. 1990. Nuclear protooncogenes Fos and Jun. Annu. Rev. Cell Biol. 6: 539-557.

Rauscher, F.J. III, P.J. Voulalas, B.R. Franza, and T. Curran. 1988. Fos and Jun bind cooperatively to the AP-1 site: Reconstitution in vitro. Genes \& Dev. 2: 1687-1699.

Roman, C., L. Cohn, and K. Calame. 1991. A dominant negative form of transcription activator mTFE 3 created by differential splicing. Science 254: 94-97.

Sadowski, I. and M. Ptashne. 1989. A vector for expressing GAL4(1-147) fusions in mammalian cells. Nucleic Acids Res. 17: 7539.

Sadowski, I., J. Ma, S. Triezenberg, and M. Ptashne. 1988. GAL4VP16 is an unusually potent transcriptional activator. $\mathrm{Na}$ ture 335: 563-565.

Santoro, C., N. Mermod, P.C. Andrews, and R. Tjian. 1988. A family of human CCAAT-box-binding proteins active in transcription and DNA replication: Cloning and expression of multiple cDNAs. Nature 334, 218-224.

Sassone-Corsi, P. L.J. Ransone, W.W. Lamph, and I.M. Verma. 1988. Direct interaction between fos and jun nuclear oncoproteins: Role of the "leucine zipper" domain. Nature 336: 692-695.

Scharfmann, R., J.H. Axelrod, and I.M. Verma. 1991. Long term in vivo expression of retrovirus-mediated gene transfer in mouse fibroblast implants. Proc. Natl. Acad. Sci. 88: 46264630 .

Scheurmann, M., M. Neuberg, J.B. Hunter, T. Jenuwein, R.P. Ryseck, R. Bravo, and R. Mueller. 1989. The leucine repeat motif in fos protein mediates complex formation with jun/ AP-1 is required for transformation. Cell 56: 507-516.

Triezenberg, S.J., R.C. Kingsbury, and S.L. McKnight. 1988. Functional dissection of VP16, the trans-activator of herpes simplex virus immediate early gene expression. Genes \& Dev. 2: 718-729.

Turner, R. and R. Tijan. 1989. Leucine repeats and an adjacent DNA binding domain mediate the formation of functional cFos-clun heterodimers. Science 243: 1689-1694.

Umesono, K., K.K. Murakami, C.C. Thompson, and R.M. Evans. 1991. Directrepeats as selective response elements for the thyroid hormone, retinoic acid, and vitamin $D_{3}$ receptors. Cell 65: 1255-1266.

Wisdom, R. and I.M. Verma. 1990. Revertants of v-fos-transformed rat fibroblasts: Suppression of transformation is dominant. Mol. Cell. Biol. 10: 5626-5633.

Wisdom, R. and W. Lee. 1991. The protein-coding region of c-myc mRNA contains a sequence that specifies rapid mRNA turnover and induction by protein synthesis inhibitors. Genes \& Dev. 5: 232-243.

Yen, J., R. Wisdom, I. Tratner, and I.M. Verma. 1991. An alternative spliced form of FosB is a negative regulator of transcriptional activation and transformation by Fos proteins. Proc. Natl. Acad. Sci. 88: 5077-5081.

Zerial, M., L. Toschi, R.-P. Ryseck, M. Schuermann, R. Muller, and R. Bravo. 1989. The product of a novel growth factor activated gene, fos $B$, interacts with jun proteins enhancing their DNA binding activity. EMBO I. 8: 805-813. 


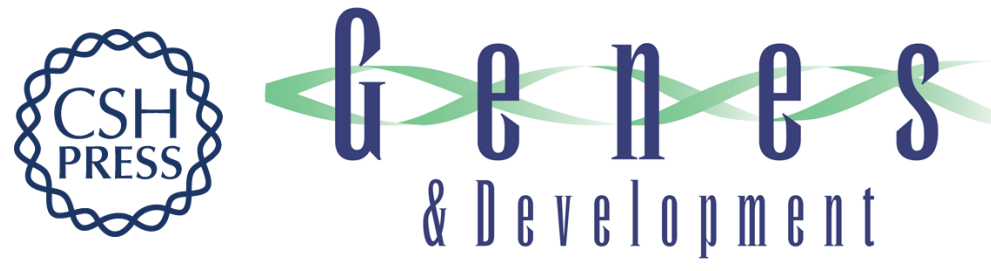

\section{Transformation by Fos $\mathrm{B}$ requires a trans-activation domain missing in FosB2 that can be substituted by heterologous activation domains.}

R Wisdom, J Yen, D Rashid, et al.

Genes Dev. 1992, 6:

Access the most recent version at doi:10.1101/gad.6.4.667

References This article cites 39 articles, 12 of which can be accessed free at:

http://genesdev.cshlp.org/content/6/4/667.full.html\#ref-list-1

License

Email Alerting

Service

Receive free email alerts when new articles cite this article - sign up in the box at the top right corner of the article or click here.

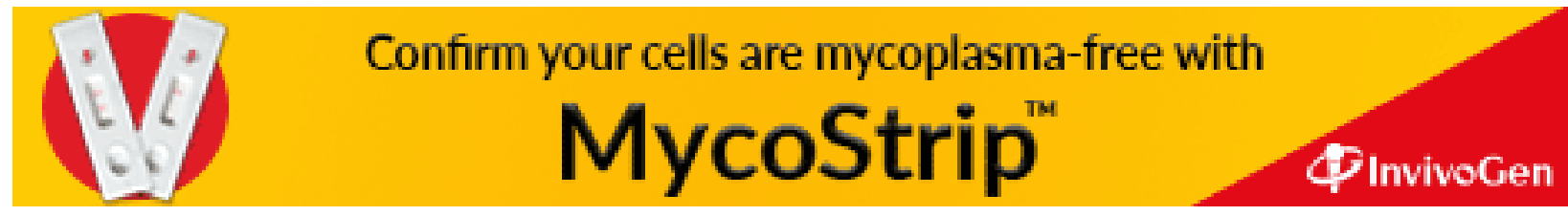

